\section{A bio-friendly future}

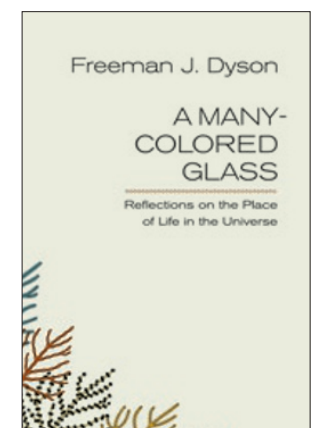

A Many-Colored Glass: Reflections on the Place of Life in the Universe

\section{by Freeman J. Dyson}

University of Virginia Press, 2007

160 pages, hardcover, $\$ 21.95$

ISBN 0813926637

\section{Reviewed by \\ Linda MacDonald Glenn}

Are you a hedgehog or a fox? Isaiah Berlin's descriptive dichotomy is 윽 based on the ancient Greek poet Archilochus' fragment of verse, "The fox knows many things, but the hedgehog knows one big thing" Freeman J. Dyson recognizes that scientists come in these two different flavors and explains the difference as he sees it: "Foxes are broad, hedgehogs are deep. Foxes are interested in everything and move easily from one problem to another. Hedgehogs are interested in only a few problems that they consider fundamental, and stick with the same problems for years or decades." He readily admits that science needs both: Einstein was a hedgehog; Fermi was a fox.

So is Dyson a hedgehog or a fox? He is a theoretical physicist and mathematician, professor emeritus of physics at the Institute of Advanced Study, a member of the National Academy of Sciences and a fellow of the Royal Society of London. He is also an unabashed optimist, and his writing reflects his effulgent worldview. What makes A Many-Colored Glass - a collection of Dyson's lectures on the general theme of life in the universe-so exceptional is that the content is readily understandable to those who do not have an extensive background in science. On the other hand, it does help to have at least a smattering of science knowledge as he discusses the second law of thermodynamics and Oort clouds.

The first lecture, “The Future of Biotechnology," has Dyson envisioning the domestication of biotechnology, resulting in a new art form-as creative as painting or sculpture-and giving rise to an explosion of new and diverse creatures, few of which will be masterpieces, but which "will bring joy to their creators and variety to our flora and fauna." $\mathrm{He}$ describes a do-it-yourself biotechnology kit that will allow anyone to grow plants or animals under controlled conditions; manipulate seeds, eggs or embryos; and use tabletop instruments to sequence or synthesize substantial quantities of DNA. At the same time, he recognizes that the potential dangers of such technology are real and serious, and that five important questions need to be asked and answered as we, as a society, face this wave of the future: Can it be stopped? Ought it be stopped? If stopping it is either impossible or undesirable, what are the

Linda MacDonald Glenn is at the Alden March Bioethics Institute, Albany, New York, USA and the College of Nursing and Health Sciences, University of Vermont, Burlington, Vermont, USA.

e-mail: lindaglenn@biomedlaw.com appropriate limits that our society must impose on it? How should the limits be decided? And how should the limits be enforced nationally and internationally? Dyson does not attempt to answer these questions, but leaves them to future generations to ponder.

In the next lecture, "A Debate with Bill Joy," Dyson quotes poet John Milton's speech to Parliament in 1644 and analogizes the restraints that Sun Microsystems founder Bill Joy and others propose on biotechnological research as akin to Middle Age efforts to censor books because they present "new and dangerous ideas." Joy, in his debate with Dyson and in his articles, has proposed that scientists relinquish the pursuit of knowledge of certain technologies, such as self-replicating nanotechnology, which poses the threat of "gray goo." Dyson refutes Joy by pointing out "the long history of effective action by the international biological community to regulate and prohibit dangerous new technologies." He agrees with Joy that relinquishing pursuit of dangerous new technologies is warranted, but then argues relinquishing the pursuit of dangerous knowledge as "neither possible nor desirable."

In the third lecture, "Heretical Thoughts about Science and Society," which is also one of the more incendiary lectures in the book, Dyson attacks the "fuss about global warming" as grossly exaggerated. He explains that although he believes that climate change is real, and that it will cause problems, to focus on it as a global issue takes away time, energy and attention from more urgent issues, such as poverty, infectious disease, public education, public health, the preservation of living creatures on land and ocean, not to mention "easy problems such as the timely construction of adequate dikes around the city of New Orleans." It is in this chapter that he reveals his humanist ethic, his belief that humans are an essential part of nature: "Through human minds the biosphere has acquired the capacity to steer its own evolution, and now we are in charge. Humans have the rights and the duty to reconstruct nature so that humans and biosphere can both survive and prosper. For humanists, the highest value is harmonious coexistence between humans and nature. The greatest evils are poverty, underdevelopment, disease and hunger, all the conditions that deprive people of opportunities and limit their freedoms. The humanistic ethic accepts an increase of carbon dioxide in the atmosphere as a small price to pay if worldwide industrial development can alleviate the miseries of the poorer half of humanity. The humanistic ethic accepts our responsibility to guide the evolution of the planet." The next three lectures focus on the place of life in the universe. Here, Dyson reveals his emergent philosophy; that is, that the universe is 'bio-friendly' and creativity is intrinsic in the system. And in the final lecture, Dyson delves into theology and theofiction, exploring writings from William James to C.S. Lewis to Octavia Butler. His conclusion and overarching view is that both science and spirituality have powerful arguments that "there may be more things to heaven and earth than we are capable of understanding."

Coming back to the original question, Dyson doesn't disclose whether he thinks of himself as a hedgehog or a fox. But as he moves effortlessly from science to literature and art, then back to science and then on to religion and spirituality, he strikes me as more fox than hedgehog. Either way, Dyson's compilation of lectures makes for engrossing and provocative reading for both scientists and nonscientists alike.

1. Berlin, I. The Hedgehog and the Fox: An Essay on Tolstoy's View of History (Elephant Paperbacks, Chicago; 1993). 